\title{
Relações Públicas e Comunicação Organizacional em discussão
}

\author{
Public Relations and Organizational \\ Communication under discussion
}

\author{
Relaciones Públicas y Comunicación \\ Organizacional en discusión
}

\section{Celsi Brönstrup Silvestrin}

- Doutora em Ciências da Comunicação pela Escola de Comunicações e Artes da Universidade de São Paulo (ECA-USP)

- Mestre em Comunicação Social pela Universidade Metodista de São Paulo (Umesp)

- Especialista em Marketing Empresarial pela Universidade Federal do Paraná (UFPR)

- Bacharel em Relações Públicas pela Universidade Federal de Santa Maria (UFSM)

- Professora associada e coordenadora do Curso de Comunicação Social da Universidade Federal do Paraná (UFPR)

- Coordenadora da Agência Experimental de Relações Públicas da UFPR

- Organizadora da obra Gênero plural: um debate interdisciplinar (2002)

- Autora de diversos artigos em periódicos nacionais e internacionais

- celsi@matrix.com.br 
Apresenta-se breve panorama sobre as trajetórias conceituais e profissionais das áreas de Relações Públicas e de Comunicação Organizacional na realidade brasileira, com a finalidade de entender as dificuldades e os avanços nos estudos acadêmicos e a sua repercussão no campo profissional. São resgatados posicionamentos de autores brasileiros para contextualizar a reflexão sobre as convergências e os limites conceituais das áreas. Pontua-se que as interconexões entre as áreas convidam ao diálogo e que o momento propicia uma retomada das Relações Públicas.

PALAVRAS-CHAVE: RELAÇÕES PÚBLICAS • COMUNICAÇÃO ORGANIZACIONAL • TRAJETÓRIAS ACADÊMICAS

\section{Abstract}

This article presents an overview of the conceptual and professional history of Public Relations and Organizational Communication in the Brazilian context. The objective is understanding the difficulties and advances of academic studies in these fields and their repercussion on professional practice. To contextualize this reflection on convergences and conceptual limits in both fields, the positions of Brazilian authors who have presented arguments on these issues are reviewed. We find that the interconnections between these fields promote dialogue and that this conjuncture is propitious for the strengthening of Public Relations.

KEYWORDS: PUBLIC RELATIONS • ORGANIZATIONAL COMMUNICATION • ACADEMIC HISTORY

\section{Resumen}

Se presenta un breve panorama de las trayectorias conceptuales y profesionales de las áreas de Relaciones Públicas y de Comunicación Organizacional en la realidad brasileña, a fin de comprender las dificultades y los avances en los estudios académicos y su repercusión en el ámbito profesional. Para contextualizar la reflexión, las convergencias y los límites conceptuales de estas áreas, se rescatan algunos enfoques de autores brasileños que ya se pronunciaron sobre el tema. Se concluye que las interrelaciones entre las áreas invitan al diálogo y que el momento propicia una recuperación de las Relaciones Públicas.

PALABRA CLAVE: RELACIONES PÚBLICAS • COMUNICACIÓN ORGANIZACIONAL • TRAYECTORIAS ACADÉMICAS 
Darte-se do entendimento de que o exercício proposto pelo fórum da Abrapcorp $^{1}$ sobre as convergências e os limites conceituais entre Relações Públicas e Comunicação Organizacional, para fomentar a discussão sobre os campos, se, por um lado, promove abertura ao debate conceitual, por outro, será prospectivo no que diz respeito às profissões da Comunicação. Esta última temática tem a sua importância em um cenário em que a valorização da comunicação não é garantia do reconhecimento dos profissionais.

$\mathrm{Na}$ avaliação de Wolton (2006, p.104), apesar de estarem em plena expansão, as duas áreas não estão acompanhadas da mesma legitimidade que têm outras profissões. Em outras palavras, o caso aqui não é argumentar a favor de uma ou outra nomenclatura, mas estarmos atentos às novas necessidades na formação dos comunicadores, que disputam os seus lugares no mercado de trabalho, num cenário em que "todas as profissões fazem comunicação", como afirma Wolton (2006, p. 102). Nesta discussão, estarão sendo associados os interesses de pesquisadores e profissionais que se dedicam ao estudo e à prática das Relações Públicas e da Comunicação Organizacional.

\section{0 diálogo como elemento comum}

Relações Públicas e Comunicação Organizacional são áreas atuantes no Brasil desde a década de 1950, mas é a partir dos anos 1980 que a de Comunicação Organizacional se tem estabelecido de forma mais contundente, quando passou a ocupar-se "sobretudo com a perspectiva estratégica". Sua ampliação, segundo Blikstein, Alves e Gomes (2004, p.126), resultou "de uma percepção cada vez mais aguçada das profundas imbricações entre discurso, comportamento e simbolismo organizacional”.

Em decorrência dessas imbricações, observa-se que a Comunicação Organizacional tem instigado acadêmicos de diferentes áreas a trazerem reflexões de suas áreas de conhecimento, como da Linguística e da Administração, entre outras. Ou seja, trata-se de uma área que está aberta a incursões de especialistas com outra formação que não a Comunicação, o que fornece elementos para a construção de um quadro teórico ampliado, sem perder a sua especificidade. Os estudos sobre Comunicação Organizacional no Brasil, em parte encaminhados com base em perspectivas teóricas traçadas por autores internacionais, têm obtido importantes contribuições de pesquisadores nacionais, cujos trabalhos auxiliam na delimitação da área de conhecimento, a qual vem se consolidando no meio acadêmico.

1 A Associação Brasileira de Pesquisadores de Comunicação Organizacional e de Relações Públicas (Abrapcorp) inclui em seus congressos anuais um Fórum sobre as Bases Conceituais de Comunicação Organizacional e de Relações Públicas. 0 I Fórum foi realizado no II Congresso Abrapcorp (Belo Horizonte, 2008) e o II Fórum, no III Congresso Abrapcorp (São Paulo, 2009). 
O artigo "Comunicação Organizacional:certezas e incertezas", de Scroferneker (2008), ao mesmo tempo em que nos dá um significativo mapeamento dessas principais contribuições teóricas, assinala a importância que é dada à interação e à busca do diálogo entre as organizações e os seus públicos, aspectos essenciais também nos estudos e na prática das Relações Públicas. Poyares (1974, p. 210) defendia o diálogo como condição para a realização das ações de relações públicas, enfatizando a "necessidade de estabelecer a dupla via de comunicação, campo das operações de RP - falar e ouvir, para ser ouvido quando falar - ou antes, estabelecer o diálogo", explicando que "descobrir os fundamentos desse diálogo, aprimorar os instrumentos para a sua realização, constitui o objeto destes nossos estudos".

Se partirmos da perspectiva de que Relações Públicas e Comunicação Organizacional estão alicerçadas em fundamentações teóricas que fazem parte do escopo da Comunicação, pode-se dizer que as indagações sobre "os fundamentos desse diálogo" são de interesse das duas áreas, assim como outros elementos que fazem parte dos processos comunicativos e das práticas discursivas existentes entre as organizações e os públicos.

\section{Sobre a aproximação das áreas}

Margarida Kunsch (2003, p. 119-120) afirma que as interfaces entre Relações Públicas e Comunicação Organizacional são uma realidade no Brasil, explicando que, "para compreender e aplicar os fundamentos teóricos de Relações Públicas, é necessário também conhecer o espectro da abrangência de Comunicação Organizacional e das áreas afins”. Para Oliveira (2007, 141), as Relações Públicas devem ser compreendidas como um subcampo da Comunicação Organizacional, entendida [...] como o campo da comunicação nas organizações, locus de atuação do comunicador/relações-públicas, cujo aspecto é considerado fundamental para a autora ao referir-se à formação acadêmico-profissional em Relações Públicas.

Já no entendimento de França e Ferrari (2007), as áreas de Relações Públicas e de Comunicação Organizacional permanecem submetidas à Comunicação, a qual reconhecem como a grande área "que engloba debaixo do seu conceito diversas outras áreas, cada uma com suas características específicas, porém diferenciadas nos seus objetivos e nas suas aplicações”, como buscam demonstrar na construção da "árvore da Comunicação". Esses autores ainda fazem uma distinção entre Comunicação e Comunicação Organizacional, entendendo que não cabe elevar a Comunicação Organizacional à mesma categoria da Comunicação, como vem ocorrendo. Enfatizam que Relações Públicas é uma área da Comunicação, a única habilitação de Comunicação Social "à qual compete por natureza a função de planejar e fazer a gestão de assuntos públicos e das políticas institucionais permanentes da organização diante de seus públicos estratégicos, que compõe suas subáreas". Esclarecem que a força das 
Relações Públicas está na "sua função legítima de interlocutora e gestora das políticas corporativas de relacionamentos simétricos da organização perante os seus públicos, tendo por alvo contribuir de maneira efetiva para o sucesso de seus negócios" (FRANÇA; FERRARI, 2007, p. 7-8).

Apesar da divergência que pode haver na compreensão desses autores sobre as delimitações das áreas, há um entendimento comum sobre a interconexão das mesmas, propiciando o diálogo e a reflexão sobre as profissões de Comunicação, principalmente quanto à formação do profissional de relações públicas.

\section{As profissões da Comunicação}

Nesse cenário, observa-se uma abertura para a diversificação profissional na área de Comunicação, conforme constatado por Kunsch (2004, p. 121-139) na pesquisa ${ }^{2}$ sobre a prática comunicacional nas organizações. Os resultados demonstram que, apesar do crescimento da valorização da comunicação nas organizações, embora ainda não com um posicionamento estratégico, como esclarece a autora, a maioria dos responsáveis por essa área nas organizações pesquisadas não é formada em Comunicação Social. Para Wolton (2006, p. 108), "hoje, as funções ligadas à Comunicação, relacionadas com a tecnologia, o trabalho, as relações humanas, são necessárias, mas não valorizadas”. Afirma ser necessário falar das profissões da Comunicação, para mostrar a importância e a onipresença da comunicação nas nossas sociedades (WOLTON, 2006, p. 110).

Sem dúvida, temos que levar em conta a necessidade do reconhecimento público/social da profissão, mediante a compreensão e a aceitação do que ela tem a oferecer para a sociedade e do que ela aufere de benefícios por intermédio do seu exercício. Não se consegue isso simplesmente pela legitimidade legal/jurídica da profissão.

Por outro lado, é fundamental que o profissional, no exercício ético de sua função, possa garantir a sua sobrevivência digna. Cabe esclarecer que, ao fazermos referência ao reconhecimento social da profissão, não nos restringimos necessariamente aos modelos tradicionais com base na regulamentação vigente, mas já vislumbrando um novo panorama das profissões.

\section{Considerações finais}

Percebe-se, assim, que o desenvolvimento de uma área fortalecerá a outra. Ambas não podem prescindir de pesquisas e estudos que contribuam para a sua construção teórica e prática. A abordagem aqui feita não leva a nenhu-

2 A pesquisa de Kunsch teve como objetivo "compreender como se processa a prática comunicacional nas organizações e qual tem sido o papel das Relações Públicas nesse contexto" (KUNSCH, 2004, p. 122). 
ma constatação específica quanto às delimitações conceituais, mas aponta elementos e interesses comuns às áreas, com interconexões frequentes entre ambas e com outras disciplinas, que propiciam e convidam ao diálogo. Delineia-se, além disso, um momento propício para redimensionar as Relações Públicas, com uma visão mais crítica em relação ao campo teórico e prático, bem como a formação do profissional, com a possibilidade de progredirmos na construção de uma identidade profissional mais sólida, convictos de que os estudos e as pesquisas na área de Comunicação Organizacional serão de grande valia nessa retomada.

\section{Referências}

BLIKSTEIN, Izidoro; ALVES, Mario Aquino; GOMES, Mauro Tapias. Nota técnica: os estudos organizacionais e a comunicação no Brasil. In: CLEGG, Stewart R.; HARDY, Cynthia; NORD, Walter R. Handbook de estudos organizacionais: ação e análise organizacionais. São Paulo: Atlas, 2004.

FRANÇA, Fábio; FERRARI, Maria Aparecida. Reflexões sobre uma nova proposta de classificação da comunicação e de suas áreas. In: CONGRESSO BRASILEIRO DE CIÊNCIAS DA COMUNICAÇÃO, XXX - NP de Relações Públicas e Comunicação Organizacional. Anais... Santos, SP, set. 2007. Cd-rom.

KUNSCH, Margarida M. Krohling. Tendências da produção científica em relações públicas e comunicação organizacional no Brasil. Comunicação \& Sociedade., São Bernardo do Campo, SP, PósCom-Metodista, a. 24, n. 39, p. 93-126, 1. sem. 2003.

A função das relações públicas e a prática comunicacional nas organizações. Organicom - Revista Brasileira de Comunicação Organizacional e Relações Públicas, Gestcorp/ECA-USP, a. 1, n. 1, p. 120-139, ago. 2004.

OLIVEIRA, Ivone de Lourdes. Formação acadêmico-profissional em relações públicas: uma perspectiva contemporânea. In: KUNSCH, Margarida M. Krohling (Org.). Ensino de comunicação: qualidade na formação acadêmico-profissional. São Paulo: ECA-USP / Intercom, 2007.

SCROFERNEKER, Cleusa M. Andrade. Comunicação organizacional: certezas e incertezas. In: SCROFERNEKER, Cleusa M. Andrade (Org.). 0 diálogo possível: comunicação organizacional e paradigmas da complexidade. Porto Alegre: Edipucrs, 2008.

WOLTON, Dominique. É preciso salvar a comunicação. São Paulo: Paulus, 2006. 